\title{
Association of Lead in Maternal Serum with Fetal Neural Tube Defects (NTDs)
}

Dr. Fahmida Bayes Kakan ${ }^{1 *}$, Professor Dr. Firoza Begum ${ }^{2}$, Professor Dr. Nahreen Akhtar ${ }^{3}$, Shamshad Begum Quraisi ${ }^{4}$, Dr. Tabassum Perveen ${ }^{5}$, Dr. Mst. Tajmira Sultana ${ }^{6}$, Dr. Mohammad Saifullah Ahtesam ${ }^{7}$

${ }^{1}$ Junior Consultant, Department of Gynecology and Obstetrics, UHC Mirzapur, Tangail, Bangladesh

${ }^{2}$ Ex-Chairman and Professor, Department of Feto Maternal Medicine, BSMMU, Dhaka, Bangladesh

${ }^{3}$ Professor and Chairman, Department of Feto Maternal Medicine, BSMMU, Dhaka, Bangladesh

${ }^{4}$ Chief Scientific Officer and Head of Chemistry Division, Atomic Energy Centre Dhaka, Bangladesh

${ }^{5}$ Associate Professor, Department of Feto Maternal Medicine, BSMMU, Dhaka, Bangladesh

${ }^{6}$ Assistant Professor, Department of Gynecology and Obstetrics, Dhaka Medical College Hospital, Dhaka, Bangladesh

${ }^{7}$ Registrar Department of Medicine, Shaheed Syed Nazrul Islam Medical College, Kishoregonj, Bangladesh

DOI: $10.36348 /$ sijog.2021.v04i02.002 $\quad$ | Received: 18.01.2021 | Accepted: 01.02.2021 | Published: 09.02 .2021

*Corresponding author: Dr. Fafmida Bayes Kakan

\section{Abstract}

Background: In human birth defects, NTDs account for 0.5-2 per 1000 pregnancies worldwide. It occurs due to abnormalities in neural tube formation. Zinc required for the absorption and synthesis of biologically active folate moiety. Its deficiency creates a lack of folate in metabolic activity. Lead competes with zinc and slowly decreases zinc stores in the body. It causes morphological changes and gives an incomplete blood-brain barrier to the developing nervous system. Objective: The objective of the study was to find out the associations between maternal serum lead concentration and fetal NTDs. Materials and Methods: It was a case-control study conducted in Feto- Maternal Medicine Unit, Department of Obstetrics and Gynecology, Bangabandhu Sheikh Mujib Medical University, Dhaka, Bangladesh, from January 2016 to June 2016. Ethical clearance was taken. A total of 60 pregnant women were selected as the study population. 30 with USG detected fetal NTDs case and 30 with normal fetus. In both groups folic acid level was normal. Maternal serum was taken for measuring lead by Graphite furnace automatic absorption spectrophotometer. Data were analyzed by SPPS version 17. Results: The raised value of serum lead was found in $6.67 \%$ of patient with fetal NTD. Relationship between NTD and raised value of lead were found significant. Conclusion: From this study, we concluded, raised serum lead level is one of the associated factors for fetal neural tube defects.

Key words: Lead, fetal NTDs.

Copyright () 2021 The Author(s): This is an open-access article distributed under the terms of the Creative Commons Attribution 4.0 International License (CC BY-NC 4.0) which permits unrestricted use, distribution, and reproduction in any medium for non-commercial use provided the original author and source are credited.

\section{INTRODUCTION}

Neural tube defects are the most common severe congenital defects of the central nervous system. NTD refers to a heterogeneous and complex congenital anomaly of the CNS, that occur due to abnormalities in neural tube formation. These abnormalities are secondary to faulty neural tube closure that occurs in the third and fourth gestational weeks. It creates basic defects which occur anywhere along the neuroaxis from the developing brain to the sacrum. NTD is one of the important causes of perinatal mortality and morbidity. After cardiac anomalies it is the second most common cause of perinatal death in USA [1]. The prevalence of
NTD varies greatly, depending on ethnic, racial and socio-economic backgrounds. The mortality and morbidity rates are high: $20 \%$ of affected infants die within the first year, 37\% within the first decade, $44 \%$ within the second and the survival rate beyond the third decade is only $50 \%$ [2]. Total $88 \%$ of the surviving infants suffer from variable degrees of life-long disabilities and are at risk for psychosocial maladjustment [3], although the intellectual performance may be normal in the vast majority of cases [4]. The incidences of NTDs may vary by race, geographical area, socioeconomic class, nutritional status and multiple predisposing factors. The spectrum is wide. It ranges from $1 / 1000$ live births in parts of 
Fahmida Bayes Kakan et al; Sch Int J Obstet Gynec, Feb. 2021; 4(2): 29-34

china to about $1 / 5000$ live births in Scandinavian countries. Worldwide incidence is 0.5 to $2 / 1000$ live birth [5]. In the United States, the incidence of NTD is estimated at 1 in 1000 live births, and open Spina bifida is 0.6 to $0.8 / 1000$ live births, anencephaly is 0.6 to $0.8 / 1000$ live births. In major cities of India, hospital based record showed 3.9 to $8.8 / 1000$ live births and in rural areas showed 6.57 to $8.21 / 1000$ live births of NTDs. But the figure hasn't changed much over the past 10 years in India where prevalence is still 4.5/1000 live births [6]. In embryonic life, the central nervous system develops from neural tube which is formed by the process of neuralation. There are two distinct phases of neurulation. The brain and the neural tube form from the caudal region to the upper sacral level in primary phase. Secondary neurulation completes the distal sacral and coccygeal regions. Current concepts of neural tube developments are related to the principle of convergent extension, seemingly to direct the lengthening of cells to make the embryonic axis. This process is likely controlled by PCP, the process in which cells are aligned and become polarized within epithelium. These complex pathways are being regulated by multiple genes [7]. The cranial end of neural tube becomes the forebrain, midbrain and hindbrain. The caudal end becomes the spinal cord. Failure of neurulation at any stage leads to formation of neural tube defects [8]. Each closure site may be modified by unique genetic or environmental factors during the process of development. There are several types of NTDs. Anencephaly, the most severe defect, characterized by the absence of the brain and cranium above the base of the skull and orbits. Another is termed as cephalocele which is the herniation of meninges and brain tissue through a defect in the cranium, typically an occipital midline defect. Spina bifida occurs when one or more vertebral arches fail to fuse, so that meninges with or without neural tissue protrude under the skin. Hydrocephalus is the dilatation of the fetal ventricular system with increased intraventricular pressure. In $70 \%$ to $90 \%$ of the cases, hydrocephalus is associated with Spina bifida and termed as Arnold-chiari malformation [8]. Moreover, it can be classified into two groups, i.e Defects affecting cranial structures and defects involving spinal structures. NTDs are currently considered as "complex" genetic disorders meaning that both genetic and environmental factors can be shown to play a role in causation [9]. There are some maternal factors like age, parity, previous pregnancy wastage, multiple gestation, obesity, illness, socioeconomic status, occupational exposure, dietary factors and other factors [10]. Other factors include nutritional factors, and maternal illnesses are also responsible. Among the nutritional factors, trace elements and vitamins play an important role. Among the other factors excess of vitamin A, Zinc deficiency, high level of Lead and organic matter in drinking water have all been associated with higher NTD but not consistently. Lead is an environmentally persistent toxin. It is a systemic toxicant, affecting virtually every organ system. It primarily affects the CNS particularly the developing brain. Consequently, it's neurotoxic effect starts from fetal brain. It causes morphological changes in the developing nervous system and gives rise to incomplete blood brain barrier in the developing nervous system [11]. The direct neurotoxic actions include apoptosis, excitotoxicity affecting neurotransmitter storage and release. It also acts by altering neurotransmitter receptors, mitochondria and second messengers in cerebrovascular endothelial cells, astroglia and oligodendroglia [11]. Lead strives with Zinc and crosses into the gut wall and slowly decreases the Zinc supplies in the body and replaces them with Lead. Zinc is required in the absorption and synthesis of biologically active folate moiety. In the state of Zinc deficiency, folate level falls in the metabolically active cells. As a result, the DNA repair and nucleic acid biosynthesis are largely affected in the rapidly developing embryo that leads to NTD and other abnormalities [12]. Centers for Disease Control and Prevention in the US declared that in general population blood Lead level should be $<10$ microgram/dl [13]. Pregnancy is a state of high sensitivity to toxic substances. Blood Lead level increases during pregnancy either from endogenous source or from ambient pollution and affects health in pregnancy and could be extremely harmful to mother and the growing fetus [14]. Bone Lead stores are mobilized during periods of increased bone turnover such as pregnancy and lactation for women with prior Lead exposure. Sustained exposure of Lead may increase arterial blood pressure and results in pregnancy induced hypertension or preeclampsia, cognitive decline, defects in hematopoietic and renal impairment. It also results in spontaneous abortion, alteration of fetal characteristics like neural tube defect, low birth weight and preterm labor [15]. Blood Lead concentration is the primary biomarker used for monitoring exposure levels, and reflects an individual's current body Lead burden [16]. Blood Lead levels increase during pregnancy because of increased gastrointestinal absorption and an increase in bone turnover. During pregnancy, there is increase in bone resorption to accommodate the mineral needs of the fetus, which may lead to transient increases in endogenous serum Lead level. In pregnancy or women considering pregnancy, Lead level should be $<5$ micrograms/dl. Patients with higher Lead level should receive specific nutritional recommendations of $2000 \mathrm{mg}$ of calcium and $60 \mathrm{mg}$ of iron [13]. Ln some studies associations of high level Lead were found job related. The resultant uncertainty regarding the actual magnitude of exposure makes it difficult to characterize the dose-response relationship quantitatively [17]. It has been determined that Lead crosses the placental barrier with fetal uptake, beginning at 12 weeks of gestation and continuing throughout development up to birth. Concentrations of Lead in umbilical cord were found to be $80 \%$ to $100 \%$ of the maternal blood lead level [18]. 
Fahmida Bayes Kakan et al; Sch Int J Obstet Gynec, Feb. 2021; 4(2): 29-34

\section{MATERIALS AND METHODS}

It was a comparative case control study, conducted at the Department of Obstetrics and Gynecology, Bangabandhu Sheikh Mujib Medical University in collaboration with Clinical Pathology Department of BSMMU and Atomic Energy Center, Dhaka, Bangladesh. The study period was from January to June 2016. A total number of 60 pregnant women attending the OPD for routine antenatal care after first trimester were selected as study population. Out of total 60 pregnant women, 30 had USG detected fetal neural tube defects with normal level of serum folic acid (case group) and the rest 30 women had USG detected normal fetus with normal level of serum folic acid (control group). Ethical clearance was taken from the concerned department and Institutional Review Board(IRB). Obstetric history included consanguinity, gestational age, parity and previous NTD's affected child, personal history regarding smoking, H/O betel nut or tobacco chewing. Period of gestation was confirmed by recording CRL in early ultrasound or by measuring BPD in mid trimester ultrasound. $5 \mathrm{cc}$ of blood sample was collected from median antecubital vein through venipuncture. Blood was allowed to clot formation in a plain test tube for analysis of folic acid and Lead. Collected blood was centrifuged at $3000 \mathrm{rpm}$ for 5 minutes. Separated serum was collected into equal half amount into two plastic micro centrifuged tubes. One was used for detection of serum folic acid level and another serum sample was kept at $-20^{\circ} \mathrm{c}$ in lab for analysis of Lead. When the first sample analysis showed normal serum folic acid level, concentration of Lead $(\mathrm{Pb})$ determination was made by using Graphite furnace atomic absorption spectrophotometer, in Analytic chemistry laboratory of chemistry division, Atomic Energy Center. Data were analyzed by SPSS version 17. Results were presented in tables, figures and diagrams. Deference in demographic variables between the case and control were compared by chi-square test. Mean values of lead was compared between the case and the control by unpaired $t$ test. Presence of NTDs was considered as the dependent variable in statistical analysis. The correlation between maternal serum lead levels with maternal age was shown by Pearson's correlation test.

\section{RESULTS}

Table-I: Participants Age Distribution ( $N=60)$

\begin{tabular}{|c|c|c|c|c|}
\hline Age(in years) & Case $(n=30)$ & Control $(n=30)$ & Total $(\mathrm{N}=60)$ & P-Value \\
\hline$\leq 20$ & $3(10.0)$ & $2(6.67)$ & $5(8.33)$ & \multirow[t]{4}{*}{$>0.05^{\mathrm{ns}}$} \\
\hline $20-30$ & $24(80.0)$ & $24(80.0)$ & $48(80.0)$ & \\
\hline $31-40$ & $3(10.0)$ & $4(13.33)$ & $7(11.67)$ & \\
\hline Base & $30(100.0)$ & $30(100.0)$ & $60(100.0)$ & \\
\hline Mean age \pm SD & $26.36 \pm 4.57$ & $25.56 \pm 5.28$ & $25.83 \pm 4.93$ & \\
\hline Age range (years) & $19-37$ & $18-35$ & $18-35$ & \\
\hline
\end{tabular}

Table I shown that out of 60 participants maximum $83.33 \%$ respondents were from $21-30$ years' age group. The mean age of cases was $25.83 \pm 4.93$ years (Age range: 19-37 years) and control were 25.56 \pm 5.28 years. (Age range: 18-35 years). No significant difference was found among the age distribution of case and control $(\mathrm{p}=>0.05)$.

Table-II: Distribution of Independent Variables of Participants $(\mathrm{N}=60)$

\begin{tabular}{|c|c|c|c|c|}
\hline Independent factors & Case $(n=30)$ & Control $(n=30)$ & Total $(\mathrm{N}=60)$ & P Value \\
\hline \multicolumn{2}{|c|}{$\mathrm{H} / \mathrm{O}$ previous NTD baby } & & & \multirow[t]{3}{*}{$>0.05^{\mathrm{ns}}$} \\
\hline Present & $2(6.67 \%)$ & $1(3.33 \%)$ & $3(5.00 \%)$ & \\
\hline Absent & $28(93.33 \%)$ & $29(96.67 \%)$ & $57(95.00 \%)$ & \\
\hline \multicolumn{4}{|l|}{ H/O Consanguinity } & \\
\hline Yes & $5(16.67 \%)$ & $7(23.33 \%)$ & $12(20.00 \%)$ & \multirow[t]{3}{*}{$<0.05^{\mathrm{s}}$} \\
\hline No & $25(83.33)$ & $23(76.67 \%)$ & $48(80.00 \%)$ & \\
\hline \multicolumn{4}{|l|}{ Smoking } & \\
\hline Yes & $0(0 \%)$ & $0(0 \%)$ & $0(0 \%)$ & \\
\hline No & $30(100 \%)$ & & $60(100 \%)$ & \\
\hline \multicolumn{4}{|l|}{ Tobacco chewing } & \\
\hline Yes & $1(3.33 \%)$ & $0(0 \%)$ & $1(1.67)$ & \\
\hline No & $29(96.67 \%)$ & $30(100 \%)$ & $59(98.33)$ & \\
\hline \multicolumn{4}{|l|}{ Betel nut } & \\
\hline Yes & $1(3.33 \%)$ & $0(0 \%)$ & $1(1.67)$ & \\
\hline No & $29(96.67 \%)$ & $30(100 \%)$ & $59(98.33)$ & \\
\hline
\end{tabular}


Table II shown, no significant difference was found in tobacco chewing, betel nut between case and control. Consanguinity was found statistically significant in number among control group. All the cases in the study group were nonsmoker.

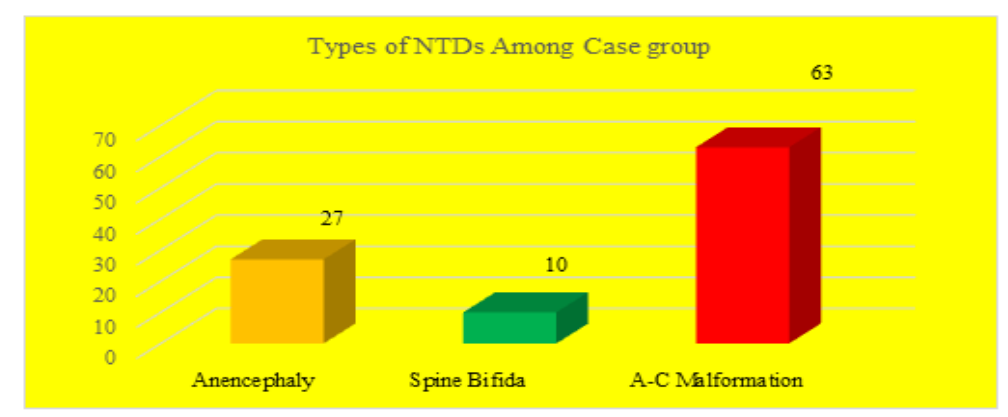

Fig-I: Types of NTDs among Case group

Figure I shown the distribution of different types NTDs among case group. Highest no of case was Arnold-Chiari Malformation (A-C Malformation).

Tabl-III: Distribution of mean Serum Folic Acid Level of Participants ( $N=60)$

\begin{tabular}{|l|l|l|l|}
\hline Serum Folic Acid $(\mathbf{n g} / \mathbf{m l})$ & Mean \pm SD $(\mathbf{n g} / \mathbf{m l})$ & Normal Range of Folic Acid & $\mathbf{p}$ value \\
\hline Case & $\mathbf{9 . 5 5 + 2 . 1 7}$ & $2.7-16.1 \mathrm{ng} / \mathrm{ml}$ & $\mathbf{0 . 7 4 7} \mathbf{n s}$ \\
\hline Control & $\mathbf{9 . 7 9 + 2 . 1 7}$ & & \\
\hline
\end{tabular}

Table III shows mean serum folic acid in case $9.55+3.64 \mathrm{ng} / \mathrm{ml}$ and in control $9.79+2.17 \mathrm{ng} / \mathrm{ml}$.
Unpaired $\mathrm{t}$ test showed that the difference was statistically not significant

Table-IV: Distribution of Serum Lead Level of Participants (N=60)

\begin{tabular}{|l|l|l|l|l|}
\hline Serum lead level & Case & Control & Total & p Value \\
\hline $\begin{array}{l}\text { Normal } \\
(<5 \mu \mathrm{gm} / \mathrm{dl})\end{array}$ & $28(93.33 \%)$ & $30(100 \%)$ & $58(96.67 \%)$ & $<0.000^{\mathrm{s}}$ \\
\hline High $(>=5 \mu \mathrm{gm} / \mathrm{dl})$ & $2(6.67 \%)$ & $0(0 \%)$ & $2(3.33 \%)$ & \\
\hline
\end{tabular}

Table IV: shown that serum lead was found normal in all control and 28 cases, however raised level was found in $6.67 \%$ cases which is statistically highly significant

Table-IV: Mean Values of Serum lead level Among Study Populations ( $n=60)$

\begin{tabular}{|c|c|c|c|c|c|}
\hline \multirow[t]{2}{*}{ Participant group } & \multirow{2}{*}{$\begin{array}{l}\text { Mean } \pm \text { SD } \\
\text { Serum Level }(\mu \mathrm{gm} / \mathrm{dl})\end{array}$} & \multirow[t]{2}{*}{ Value of t-test } & \multicolumn{2}{|c|}{$95 \%$ CI of difference } & \multirow[t]{2}{*}{ p Value } \\
\hline & & & Lower & Upper & \\
\hline Case & $3.25 \pm 1.12$ & \multirow[t]{2}{*}{-3.809} & \multirow[t]{2}{*}{-1.43} & \multirow[t]{2}{*}{-0.044} & \multirow[t]{2}{*}{$\mathbf{0 . 0 0 0}^{\mathrm{s}}$} \\
\hline Control & $2.32 \pm 0.75$ & & & & \\
\hline
\end{tabular}

Table IV: shown that mean serum lead level was $3.25 \pm 1.12$ in case and among the control was 2.32 \pm 0.73 and the comparison of difference between two means by unpaired t-test found significant.

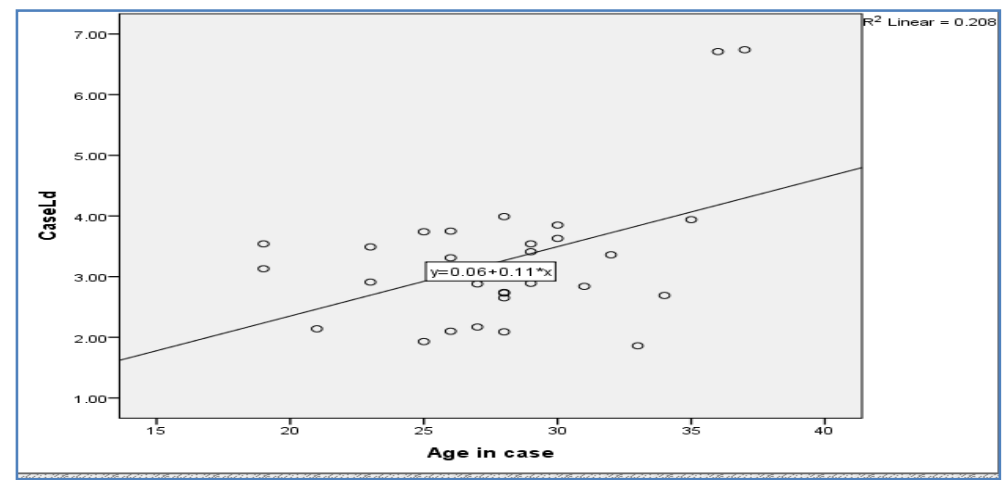

Fig-II: Correlation between age of samples and their serum lead level $(n=30)$ 
Fahmida Bayes Kakan et al; Sch Int J Obstet Gynec, Feb. 2021; 4(2): 29-34

Figure II: shows that the significant relationships of level of serum lead with age of the cases. 2 cases with elevated serum lead level showed the advanced age ( $>35$ years).

\section{DISCUSSION}

Neural tube defect is a complex process. It is one of the commonest birth defect. Both genetic and environmental factors are contributing for developing NTD [19]. Folic acid deficiencies are an established risk factor for NTDs. In this study all the samples of NTDs had normal Folic acid level which excludes its role in developing NTDs. Considering the teratogenicity of Lead, CDC declared that blood Lead level should not $>5 \mathrm{ug} / \mathrm{dl}$ during pregnancy or women who are going to become pregnant. CDC also recommended that maternal and umbilical cord blood should be measured at delivery in high risk population [13].

Maternal age is an important factor for NTDs. Whiteman et al. stated that women aged more than 35 years had a substantially increased risk of having an NTD affected pregnancy [20]. This study showed the mean $( \pm \mathrm{SD})$ of age of cases was $26.36 \pm 4.57$ years, which is slight more than the control group.

The sub classification of NTD in this study showed that $63 \%$ of NTD fetuses were born with Arnold - Chiari malformation, 27\% were born with anencephaly and rest $10 \%$ had isolated spina bifida. Among the Arnold Chiari malformation open Spina bifida with hydrocecphlous comprises $50.7 \%$ followed by anencephaly with Spina bifida (42.9\%) and encephalocele $6.3 \%$. In this study raised serum lead levels were found in 1 case with Arnold-Chiari malformation and 1 case with anencephaly mother.

Out of 30 cases 5 mothers (16.67\%) experienced NTD in their $4^{\text {th }}$ pregnancy. Among them, $2(6.67 \%)$ had the previous history of NTD baby. Whiteman et al. showed that $4^{\text {th }}$ deliveries had the higher risk of NTD [21]. Findings regarding recurrence in this study also support previous report which showed that in $2.5 \%$ cases recurrence may occur [22].

This study showed that significant number of cases had high level of serum lead than control group. The mean $( \pm \mathrm{SD})$ serum Lead in case group found statistically highly significant $(\mathrm{P}=0.000)$. But the source of lead in this study was not assessed. In this study out of 30 cases $2(6.6 \%)$ had elevated serum lead level and both these cases were $>35$ years which showed the significant relationship of the serum lead with age of the cases like the study of Whiteman [21].

Regarding the consanguinity, Murshid et al. reported that consanguinity is a significant risk factor for NTD [19]. In this study no cases had history of consanguineous marriage.

\section{CONCLUSION}

In this case control study we found raised serum lead level was $6.67 \%$ in case group. The difference between mean value of serum Lead among case and control groups were statistically significant. Advanced age of the mother ( $>35$ years) also showed a significant relationship in elevated level of lead. So, from this study, we concluded, raised serum lead level is one of the associated factors of fetal neural tube defects.

\section{REFERENCES}

1. Golalipour, M. J., Vakili, M. A., Mansourian, A. R., \& Mobasheri, E. (2009). Maternal serum zinc deficiency in cases of neural tube defect in Gorgan, north Islamic Republic of Iran. EMHJEastern Mediterranean Health Journal, 15 (2), 337-344, 2009.

2. Hunt, G. M., \& Poulton, A. (1995). Open spina bifida: a complete cohort reviewed 25 years after closure. Developmental Medicine \& Child Neurology, 37(1), 19-29.

3. Zurmohle, U. M., Homann, T., Schroeter, C., Rothgerber, H., Hommel, G., \& Ermert, J. A. (1998). Psychosocial adjustment of children with spina bifida. Journal of child neurology, 13(2), 64-70.

4. Hagelsteen, J. H., Lagergren, J., Lie, H. R., Rasmussen, F., Börjeson, M. C., Lagerkvist, B., ... \& Köhler, L. (1989). Disability in Children with Myelomeningocele A Nordic Study. Acta Pædiatrica, 78(5), 721-727.

5. Salih, M. A., Murshid, W. R., \& Seidahmed, M. Z. (2014). Epidemiology, prenatal management, and prevention of neural tube defects. Saudi medical journal, 35(Suppl 1), S15.

6. Cherian, A., Seena, S., Bullock, R. K., \& Antony, A. C. (2005). Incidence of neural tube defects in the least-developed area of India: a population-based study. The Lancet, 366(9489), 930-931.

7. Rose, N., \& Mennuti, M. (2009). Fetal neural tube defects: diagnosis, management and treatment. Glob. libr. women's med.

8. Shalal, M. M., Al-Bassam, A. N., \& Alwan, B. A. (2012). Maternal Serum Zinc level in pregnant women with second trimester induced abortion with anencephalic fetus. Journal of the Faculty of Medicine Baghdad, 54(1), 23-27.

9. Hall, J. G., \& Solehdin, F. (1998). Genetics of neural tube defects. Mental retardation and developmental disabilities research reviews, 4(4), 269-281.

10. Hendricks, K. A., Nuno, O. M., Suarez, L., \& Larsen, R. (2001). Effects of hyperinsulinemia and obesity on risk of neural tube defects among Mexican Americans. Epidemiology, 630-635.

11. Sanders, T., Liu, Y., Buchner, V., \& Tchounwou, P. B. (2009). Neurotoxic effects 
Fahmida Bayes Kakan et al; Sch Int J Obstet Gynec, Feb. 2021; 4(2): 29-34

and biomarkers of lead exposure: a review. Reviews on environmental health, 24(1), 15

12. Singla, M., Sahai, V., \& Grewal, D. S. (2009). Neural tube defects and herbal medicines containing lead: A possible relationship. Medical hypotheses, 72(3), 285287.

13. Ettinger, A. S., \& Wengrovitz, A. M. (2010). Guidelines for the identification and management of lead exposure in pregnant and lactating women.

14. Rastogi, S., Nandlike, K., \& Fenster, W. (2007). Elevated blood lead levels in pregnant women: identification of a high-risk population and interventions. Journal of perinatal medicine, 35(6), 492-496.

15. Agency for Toxic Substances and Disease Registry. (2007). Toxicological profile for lead. US Department of Health and Human Services. Atlanta, US.

16. Barbosa Jr, F., Tanus-Santos, J. E., Gerlach, R. F., \& Parsons, P. J. (2005). A critical review of biomarkers used for monitoring human exposure to lead: advantages, limitations, and future needs. Environmental health perspectives, 113(12), 1669-1674.
17. Bellinger, D.C. (2005).Teratogen update: Lead and pregnancy. Birth Defects Res AClin Mol Teratol, 409-20.

18. Papanikolaou, N. C., Hatzidaki, E. G., Belivanis, S., Tzanakakis, G. N., \& Tsatsakis, A. M. (2005). Lead toxicity update. A brief review. Medical science monitor, 11(10), RA329-RA336.

19. Murshid, W. R. (2000). Spina bifida in Saudi Arabia: is consanguinity among the parents a risk factor?. Pediatric neurosurgery, 32(1), 10 12.

20. Philip, N. Baker. (2006). Diagnosis of structural abnormalities. Obstetrics by Ten Teachers. $18^{\text {th }}$ edition. London: Hodder Arnold, 107-108.

21. Whiteman, D., Murphy, M., Hey, K., O'Donnell, M., \& Goldacre, M. (2000). Reproductive factors, subfertility, and risk of neural tube defects: a case-control study based on the Oxford Record Linkage Study Register. American journal of epidemiology, 152(9), 823-828.

22. Detrait, E. R., George, T. M., Etchevers, H. C., Gilbert, J. R., Vekemans, M., \& Speer, M. C. (2005). Human neural tube defects: developmental biology, epidemiology, and genetics. Neurotoxicology and teratology, 27(3), 515-524. 